visible. The eye tender to pressure, but not to such a degree as the right one. Moderate photophobia and lacrymation. $\mathrm{T} .=12 \mathrm{~mm} . \mathrm{Hg} ; \mathrm{V} . \mathrm{A} .=6 / 18$; glasses did not improve it.

The Wassermann blood test a few days later proved to be negative.

The right eye was enucleated two hours after the first examination of the patient. The operation showed complete atrophy of the retrobulbar tissues. The globe was drawn back to the very apex of the orbit. Not more than $3 \mathrm{~mm}$. of the optic nerve could be excised although it was cut off close to the foramen opticum. The globe contained a bony inclusion. The postoperative treatment was one usually recommended in similar cases: every four days, intravenous injections of neosalvarsan. Daily injections of cyanide of mercury. Every three days electrargol intravenously. Locally atropine, hot fomentations, etc. For days matters seemed to be going from bad to worse. The left eye was inflamed and tender. Atropine did not dilate the pupil. V. A. fell from $6 / 18$ to $1 / 20$. But on the fifth day after the operation the symptoms began to subside. The contraction of the pupil gave way, leaving a ring of pigmented residue on the anterior capsule. The fundus became visible. The vitreous was muddy, but allowed papillitis to be seen. Slow, but steady improvement began from this day, and three months after the operation the eye was quiet, the signs of the inflammation of the uvea and optic nerve had disappeared. V. A. with - 1.0 D. sph. $=6 / 12$. From time to time I have had occasion to see the patient. Her condition has not changed since.

The onset of sympathetic ophthalmitis following an injury 40 years previously is exceptional and worthy of attention.

\title{
COLOURED CRYSTALS ON THE ANTERIOR SURFACE OF THE LENSES AFFECTED BY SENILE CATARACT
}

BY

P. SANDER, M.I).

PORT SAID

Mme. E. H., French, aged 62 years, consulted me on October 3 , 1928 on account of a slight blow on her left eye, which she received while nursing her grandchild. The patient, of middle stature, a sound and energetic person, mother of many grown-up children, always enjoved excellent health. Some 15 months previously she 
consulted an oculist in France for eyesight troubles, who diagnosed commencing senile cataract in both eyes. A rapid inspection of her eyes revealed nothing particular, except commencing nuclear cataract in both eyes. But careful examination showed a striking and unusual feature, which I had never seen before. The naked-eye inspection with the usual focal illumination showed a strikingly bright reflex from the anterior surface of the lenses, reminding one of play of interference colours on fragments of antique glass. The examination by means of the corneal microscope and slit-lamp illumination revealed a great number of small coloured crystals scattered over the anterior surface of both lenses. The crystals had the appearance of tiny, fine slights of different shape, size and colour. The larger had the shape of parallelograms and rhombs, the smaller of triangles or amorphous grains. The colours were very rich and variable : cherry-red, light-red, deep yellow, sky blue, blue-green, pure green. Trembling of the eyes, or slightest oscillation of the beam caused extremely vivid play of light and colours of the crystals. They became darker, or brighter, sparkled like gems or died away. The colours were not constant : red and yellow were mutually changing, as well as blue and green. But I could not observe the change from red-yellow to blue-green and vice versa. When looked at-all was glittering and twinkling like fireworks. All the crystals were situated on the surface of thelenses. Sometimes it seemed that a part of a crystal was more or less buried in the tissue of the lens, but I am not sure whether it was really so, or if it was due to the above described play of light, when the same spot either sparkled or disappeared. Neither in the aqueous humour nor in the deeper layers of the lens could I see a single crystal. The posterior capsule was not seen owing to the nuclear opacity. I had the opportunity of examining the patient twice more. One month after her first visit I could see quite well the same crystals, but noticed a manifest decrease in their number. On February 29, 1929 - five months after the first examination, the phenomenon could not be seen any more. After careful search I found some few small amorphous grains of blue and green colour.

Coloured crystals are not rare in the lenses affected by cataract. During the last six years I have seen on several occasions coloured crystals in cataractous lensès, but never to such an extent and always more or less in the deeper layers of the lens. The drawings 205 and 280 of Vogt's magnificent atlas (French language edition) represent doubtless crystals similar to those described above, but situated at different depths of the lens (" situées à différentes profondeurs " is written on page 80 , in the legend to illustration 205). The peculiar features of my case, to which no allusion is found in existing monographs on the 
question of the microscopy of the living eye and which persuaded me to publish this case are :

(I) The abundance of crystals and their localization on the anterior capsule, and as a result of this, the extraordinary play of light and colours.

(II) The instability of this phenomenon, which disappeared in a few months.

\title{
A SHORT STUDY OF THE COMPLICATIONS OF CATARACT EXTRACTION IN EGYPT WITH SOME PRACTICAL SUGGESTIONS
}

BY

\author{
H. PÉRETZ, M.D.(Montpellier)
}

CAIRO

Mr colleagues will agree with me that in Egypt cataract may be complicated by a great many other diseases of the eye. These may affect the globe or the eyelids, but whether they be primary or of a cicatricial nature, either may hinder the good progress of the operation or jeopardize a successful issue. It is, therefore, of the greatest importance for the surgeon to be well acquainted with such complications in order that he may be better able to overcome them when they present themselves.

After 20 years of careful observation, I have been able to point out to our young Egyptian colleagues the importance of these complications, but at the same time they ought to be brought to the knowledge even of European surgeons so that, by being better acquainted with tropical ophthalmology, they will not criticize us adversely if we do not follow exactly the usual technique for cataract extraction.

In the first place, it is of interest to compare the frequency of cataract in Egypt with that in other countries, for it might appear that it is a relatively rare condition in Egypt. About a quarter of a century ago, Dr. Osborne, of Alexandria, tried to ascertain the real facts, and in his paper* "Some Characteristic Observations of the Ophthalmic Surgeon in Egypt " he compared the statistics of operations performed at the clinique of Duke Charles Theodore, of Bavaria (Munich) with those done at the European Hospital (Alexandria). The figures examined covered the period 18981907 and whilst 35.9 per cent. of the operations performed at

* Osborne.-Bulletin of the Ophthalmological Society of Egypt, p. 56, 1908. 